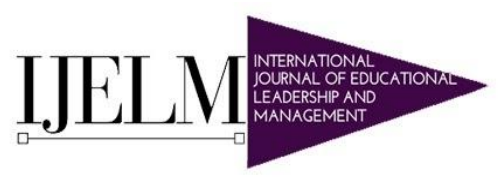

Hipatia Press

www.hipatiapress.com

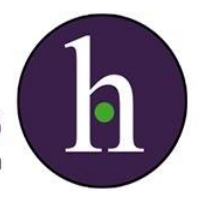

Instructions for authors, subscriptions and further details:

http://ijelm.hipatiapress.com

\title{
Improving the Performance of the Faculty of Tourism and Business Logistics for the Needs of the Business Community
}

Elizabeta Mitreva ${ }^{1} \&$ Hristijan Gjorshevski ${ }^{2}$

1) University Goce Delcev, Republic of North Macedonia

2) Ss. Cyril and Methodius University, Republic of North Macedonia

Date of publication: January $16^{\text {th }}, 2021$

Edition period: July 2020 - January 2021

To cite this article: Mitreva, E. \& Gjorshevski, H. (2021). Improving the Performance of the Faculty of Tourism and Business Logistics for the Needs of the Business Community. International Journal of Educational Leadership and Management. 9 (1), 2-27, doi: 10.17583/ijelm.2021.5409

To link this article: http://dx.doi.org/10.17583/ijelm.2021.5409

\section{PLEASE SCROLL DOWN FOR ARTICLE}

The terms and conditions of use are related to the Open Journal System and to Creative Commons Attribution License (CCAL). 


\section{Improving the Performance of the Faculty of Tourism and Business Logistics for the Needs of the Business Community}

Elizabeta Mitreva

University Goce Delcev

Republic of North Macedonia
Hristijan Gjorshevski

Ss. Cyril and Methodius University

Republic of North Macedonia

\section{Abstract}

Representatives of the business community and institutions in the Republic of North Macedonia are facing major challenges in providing a quality workforce that will be the carrier of the business sector development process. This research is part of the research conducted by the Faculty of Tourism and Business Logistics (FTBL) of the University "Goce Delchev" in Shtip in order to improve its curricula for industrial needs and the requirements of institutions in the Republic of North Macedonia. This research was carried out so to enable the Faculty to create study programs that will meet the requirements of the business community by producing a qualified workforce for achieving sustainable business systems, fostering innovation and strengthening the links between organizations, scientific research and innovations.

Keywords: Qualified workforce, higher education support, study programs, student internships. 


\section{Mejora del desempeño de la facultad de turismo y logística empresarial para las necesidades de la comunidad empresarial}

\author{
Elizabeta Mitreva \\ University Goce Delcev \\ Republic of North Macedonia
}

\author{
Hristijan Gjorshevski \\ Ss. Cyril and Methodius University \\ Republic of North Macedonia
}

\section{Resumen}

Los representantes de la comunidad empresarial y las instituciones de la República de Macedonia del Norte se enfrentan a grandes desafíos a la hora de proporcionar una fuerza laboral de calidad que sea la portadora del proceso de desarrollo del sector empresarial. Esta investigación es parte de la investigación realizada por la Facultad de Turismo y Logística Empresarial (FTBL) de la Universidad "Goce Delchev" en Shtip con el fin de mejorar sus planes de estudio para las necesidades industriales y los requisitos de las instituciones en la República de Macedonia del Norte. Esta investigación se realizó con el objetivo de que la Facultad pueda crear programas de estudio que respondan a los requerimientos de la comunidad empresarial al producir una fuerza laboral calificada para lograr sistemas de negocios sostenibles, fomentando la innovación y fortaleciendo los vínculos entre organizaciones, investigación científica e innovaciones.

Palabras clave: Desarrollo profesional docente, desarrollo de personal, educación en el servicio, director de escuela. 
$\mathbf{R}$ egardless of the number of unemployed job seekers and their level of to the assigned tasks. Hence, satisfying supply and demand with skilled labor needs to be compulsorily analyzed as a top priority in higher education. The efforts of faculties to create qualified staff become an even more important task if we are aware that the Republic of North Macedonia, as a developing country, has an uncertain economic environment and a lack of adequate economic conditions, a lack of market opportunities, and a weak consumer purchasing power. The lack of quality workforce has a great impact on the competitiveness of all organizations, and above all, on the efficiency of operations. It also reflects the increasing costs of organizations, which need longer time to find suitable workers and then train them so as to execute the assignments required of them.

Higher education institutions are aware of the necessity of redesigning the study programs profiles and the curricula quality would be depending from the obligation to reassess values, whether the study environment is tempting and etc., which all depends of the institutional leadership. The very first alteration refers to the establishing of processes of continuing improvement in all segments of higher educational institutions by involving of the academic staff, and the second by gratification of the needs to all users (students, teachers, Ministry of Education and Science, employments and professional bodies, the society as a whole and the international forum) together with the outcomes of the institution (Mitreva et al., 2016).

The Ministry of Education and Science of Republic of North Macedonia carries out its own gauge for quality efficiency within the higher education and it is usually expressed in the following manner: number of students that are completing the study programme on time with an international recognition. The quality itself within the higher education is being accomplished through many activities as part of the education and research and includes all the factors: students and professors (the human factor), educational technology, methods for quality assessment, equipment, premises, management, and finance. National Programme for the Development of Education in Macedonia expresses the desire of the state to bring about change in education that will enable compatibility of study 
programs, ecognition and recognition of degrees awarded at all levels of education in European educational space and greater employability in the European labour market. The structure of the system of quality assurance in higher education institutions correspond to regulation, although there is a deep gap between management of quality and culture of quality (Taskov \& Mitreva, 2015).

From a comparative point of view, the best solution to this problem has been applied in Switzerland, Germany and Austria, where dual education is applied. Students are involved in the business processes (real-life systems) at a very young age, and after completing secondary and higher education, they have practical experience and most often end up working in the industry or institutions where they previously completed their practical training. In this way, new qualified employees contribute significantly to the efficiency and productivity of organizations, thus helping generate greater profits for both the organizations and the system i.e. taxes and other expenses towards the state. Also, addressing this problem will further reduce unemployment, especially among young people, thereby improving the situation of their emigration, given that most of them will be employed immediately after graduation or in some cases paid during the course of their studies. In this regard, the research team of the Faculty has identified the specific goals of the project entitled: Development of Study Programs and Performance Improvement of the Faculty of Tourism and Business Logistics (FTBL) within the Goce Delchev University, Shtip for the Needs of the Business Community. The research shall identify the basic needs of the business community for qualified work potential, as well as their limitations and barriers for several success factors, in order to identify the areas where higher education support is mostly needed.

\section{Literature Review}

Globalization enables providing "European" space in higher education in order to allocate a mutual concept of competence and increased mobility of students and academic staff, as well (Sursock et al., 2010). Therefore, Europe has become the crossing point in higher education, with already set regulations 
and principles for common collaboration and usage of mutual outcomes (Smidt, 2015). Through the National Strategy for Development of Education in Macedonia, the tendency of the state to implement reforms in education that would enable compatibility of study programs, recognition of diplomas acquired in all educational degrees in each part of Europe and increased capability for employment within the European labor market, has been offered. The system structure for providing quality in higher education institutions corresponds with regulations even though there is a huge gap between quality management and the attitude of performing quality work. Higher education institutions are aware of the necessity to redesign study programs profiles and curricula quality would depend on the obligation to reassess values, whether the study environment is tempting etc., which all depends on the institutional leadership (Esyutina et al., 2013; Sin, 2012; Mosneaga \& Agergaard, 2012).

Republic of North Macedonia is a developing country that is making efforts to progress with the implementation of principles of developed European countries. When it comes to university education, with the introduction of the Bologna Declaration, numerous changes took place, in the normative (Law on Higher Education) as well as in all other areas of the organization and the performance of universities (Esyutina et al., 2013). These radical changes aimed at current and prospective students to develop their knowledge and skills more closely correlated with the needs of the labor market, but also to increase their mobility, i.e. to allow attainment of knowledge and experience in other European universities (Rosser, 2003; Lee et al., 2001).

In this modern era, the term expert is synonymous with a great connoisseur in a certain discipline. The conditions of contemporary life and work impose acquisition of numerous skills, as well as their continuous development, so the phrase lifelong learning obtained a substantial conversion. Universities are not yet a true partner in this regard, so skills upgrading is often being overtaken by companies or institutions in the field of non-formal education (Austin, 2002; Boyd et al., 2009). Education represents training and preparing the student to become a full and useful member of society, so the development of skills is only a part of the educational work. 
The second part of the paper deals with the development of critical thinking capacity and the capacity to produce knowledgeable workforce. In this regard, we need to pose the question - how much of the initiated changes take into account the basic knowledge and thought nurturing, and whether the development of the educational process performance leads to a real link between universities and organizations, scientific research and innovations (Taskov \& Mitreva, 2015; Mitreva et al., 2015).

The lack of debate over the introduction of the European Credit Transfer and Accumulation System (ECTS) is particularly evident since N. Macedonia has uncritically accepted all the proposed reforms, regardless of the possible consequences (Taskov \& Mitreva, 2015; Mitreva et al., 2015). Some European countries have already introduced changes and are trying to adapt ECTS to their needs, especially the needs of the business community (Austin \& McDaniels, 2006; Mitreva et al., 2015).

\section{Methods}

The main objective of the research, titled: Development of Study Programs and Performance Improvement of the Faculty of Tourism and Business Logistics (FTBL) for the Needs of the Business Community, is to serve the basic needs of the business community with qualified workforce potential as well as address their limitations and barriers for multiple success factors, in order to identify the areas where higher education support is mostly needed.

Another objective of the research is to identify the needs for qualified staff - graduates in business logistics with employment opportunities in the broader business sector, ministries, state and local public administration, to provide business logistics to appropriate business entities, customs services, freight forwarding, insurance companies and to work with other business entities as well as start their own businesses.

In this sense, the study focused on seven aspects. Specifically, the subject of the research was as follows: 1) the profile of managers deficient in Macedonian organizations; (business support needs); 2) what deficiencies do organizations note in their work; 3) which previous experience is considered 
necessary for any candidate to obtain a managerial position in their organization; 4) what knowledge and skills are considered necessary for the candidate to hold a managerial position in their organization; 5) how familiar they are with the study program - Business Logistics at the Faculty of Tourism and Business Logistics; 6) whether they would like to be involved in the realization of student internships in their organization where students will practically learn within real-life systems; 7) whether they would like to provide scholarships for students and will further integrate them into the organization.

In the research qualitative and quantitative methods are used. The qualitative approach comprises literature review of many publications that generally analyze the quality in higher education institutions and its implementation in practice. The quantitative approach consists of electronic survey aimed to the managers of organizations.

A combined methodological approach was used for the activities of all phases in the creation of the study and the achievement of research objectives, i.e. the analysis was done on a quantitative and qualitative level.

In respect of the quantitative part of the survey, the research team created a questionnaire to provide more information on the perceptions, attitudes, experiences and specific knowledge in view of the challenges and successes of organizations in the country in maintaining their business. The research took place from January 13 to January 17, 2020.

The questionnaire was comprised of seven separate sections: 1. Profile of managers deficient in organizations; 2 . Shortcomings noted in the operation of organizations; 3 . The need for previous experience of candidates engaged by the organization; 4. Qualifications, knowledge and skills required of any candidate for managerial positions; 5 . The organization's acquaintance with the study programs offered by FTBL; 6. Willingness of organizations to cooperate with the Faculty in the realization of student internships; 7. Willingness to scholarship students.

In addition to the seven specific questions, the questionnaire also contains a section devoted to demographic data of respondents. An online survey of a purposive sample of organizations in the Republic of North Macedonia was conducted. Data were analyzed on a quantitative level, using appropriate statistical procedures and techniques characteristic of the descriptive and 
exploratory research method. Furthermore, data were analyzed through the distribution of responses across frequencies and mean values.

Due to the subject of the research and the specific target population organizations in the Republic of North Macedonia, the most suitable for the needs of the quantitative research was the convenient, i.e. purposeful sample of respondents. One of the main goals of the research was to identify the needs for qualified staff - graduate business logistics managers with employment opportunities in the wider business sector, ministries, state and local public administration, to provide business logistics to appropriate business entities, customs services, freight forwarding, insurance companies and other business entities, as well as start their own businesses. Due to the great opportunities offered by this educational profile, the research was done across many industries. Therefore, the survey covered a total of 175 respondents organizations in the Republic of North Macedonia - according to the core business of the organizations (National Classification of Activities - NKD Rev. 2 ("Official Gazette of the Republic of Macedonia", No. 147/08) and the Law on One-Stop-Shop System and the Maintenance of the Trade Registry and the Register of Other Legal Entities ("Official Gazette of the Republic of Macedonia" No. 84/05).

Although the research was planned to be carried out among total number of 450 managers of organizations, only 175 of them have answered the questionnaire. The distribution of answers is seen visually in Figure 1. The final percentage $38,7 \%$ is relatively high which is a result of the electronic survey where the lack of personal contact caused the percentage between 1625\% (Medina-Muñoz \& García-Falcón, 2000; Bohdanowicz, et al. 2005).

It should be noted that all respondents (industry and institutions) hereinafter will bear a common name: organizations according to the interpretation of ISO 9000:2015 - Quality Management Systems - Basics and Glossary and ISO 9001:2015 - Quality Management Systems - Requirements where Organization refers to all state and public institutions that generate profit. Fig.1. 


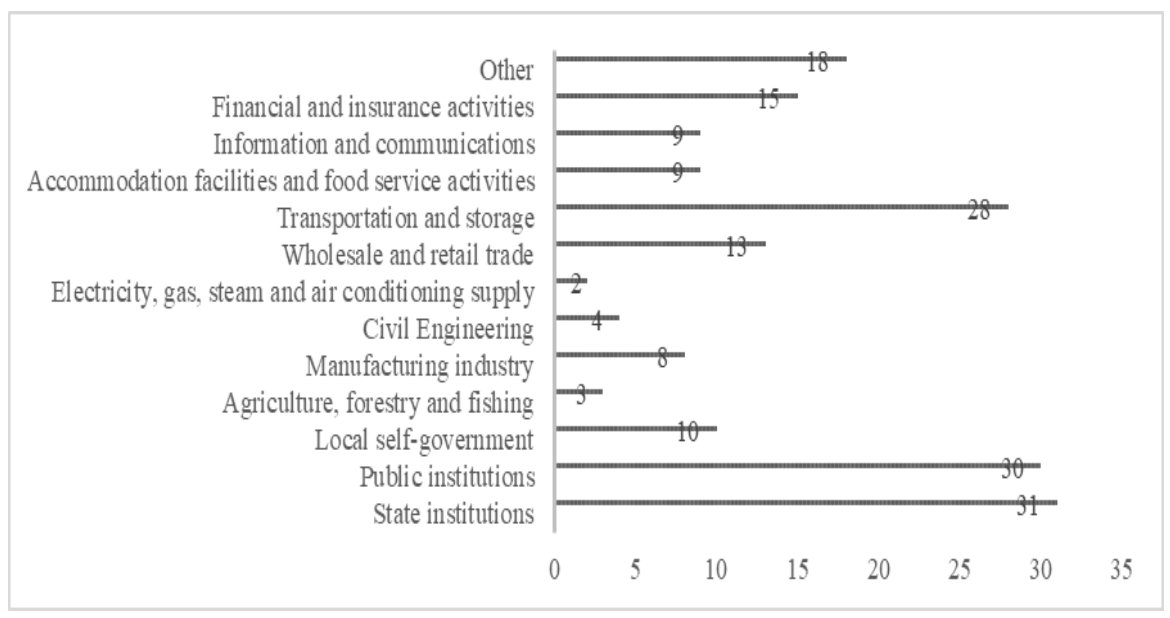

Fig.1. Sector in which organizations operate

According to Figure 1 it can be seen that the organizations for which respondents replied come from a variety of economic backgrounds. The largest number of respondents represent state institutions, public enterprises, transport and storage, finance and insurance, as well as other industries (mining and quarrying, water supply; wastewater disposal, waste management and environmental remediation services, repair of motor vehicles and motorcycles, real estate, professional, scientific and technical activities, administrative and auxiliary services, arts, entertainment and recreation, other services, household activities as employers; activities of extraterritorial organizations and bodies; household activities that produce various goods and provide different services for their own needs).

Since the research was aimed at exploring the need to create a profile of business logistics managers with employment opportunities in the wider business sector, it means that the subject of the research and the specific target population - organizations with different economic activities in R. N. Macedonia has been achieved. 
In view of the size of organizations, we divided them into micro, small, medium and large (according to the Company Law, Official Gazette No. 08 - 2019/1). Today, we live and work in times that will be remembered for the powerful effect of entrepreneurial restructuring, and the economic science increasingly points to the importance of micro, small and medium-sized enterprises as drivers of economic system restructuring which, with its toughness, vitality and inventiveness, are generators of new jobs and mobilizers of all industrial factors.

Therefore, the research focus was placed on the study of micro, small, medium, but also large organizations, with special emphasis on their role in the realization of economic activities and the contribution to the economic development of the Republic of North Macedonia.

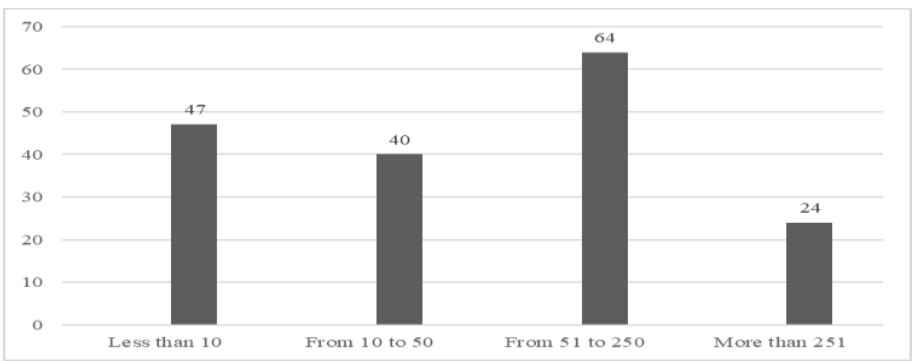

Fig.2. Size of organizations

\section{Results}

The first question relates to the profile of managers deficient in organizations. The question was posed in order to determine the needs of organizations to the extent that certain internal factors are present, with the intention of targeting higher education support needs. Respondents in this study were offered the opportunity for multiple answers.

According to the results of the respondents, the highest values were obtained for human resources managers, then quality managers, followed by managers for logistics, marketing, finance, sales, public relations and international cooperation. Lower values were obtained for distribution managers. The results are clearly shown in Figure 3. 


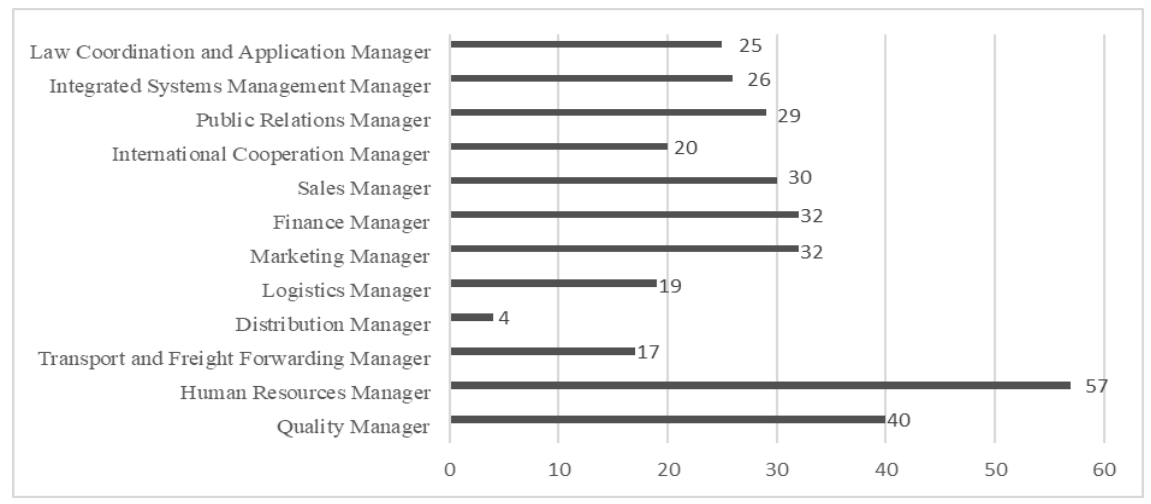

Fig.3. Profile of managers deficient in organizations

These results point to the conclusion that, coming from the objectives of the research, which is to identify the needs of Macedonian organizations for qualified potential, the results analysis has identified the areas in which the business community needs higher education support. It is precisely these areas that the Faculty should prioritize in the process of designing study programs for the needs of the business community by producing qualified workforce potential that will assist in achieving sustainable business systems.

Within the recognized and identified issues that Macedonian organizations have been striving with, it is clear that in the future they will most probably need the following occupational profiles: HR Manager; Quality Manager; Marketing Manager; Logistics Manager; Public Relations Manager; Sales Manager; Finance Manager; Transport and Freight Forwarding Manager; Manager of Integrated Management Systems Administration; International Cooperation Manager; Law Coordination and Application Manager.

Further examination of the shortcomings of organizations in their work was conducted through block questions that assessed constraints and barriers, as well as weaknesses in the organizations as internal success factors. Respondents were offered 16 statements that covered possible internal barriers to running the organization, as well as opportunities for replenishment. Respondents in this study were offered the opportunity for multiple answers. 
According to the results of the respondents, the highest values were obtained for the following statements: Undefined reward and punishment system; Insufficient investment in education and training of managers and employees; Insufficient knowledge, skills and involvement in world economic trends; Lack of skills for developing European projects according to EU criteria; Lack of developing and implementing strategies and plans.

Average values were obtained for: Lack of certification according to ISO 9001:2015; Lack of certification in other management systems (ISO 14001, 22001, 37001, 27001, 45001, 26000 etc.); Lack of effective cost tracking, and especially quality costs; Founder's lack of capacity to effectively manage company growth; The company is too small to compete in European markets.

Lower values referred to other statements, and as additional points, the respondents stated the following: No shortcomings; Unresolved laws affecting company's development; Lack of financial support from the State for growth and development of companies.

Respondents involved in the research identified the main challenges/difficulties they face in running organizations:

- Undefined reward and punishment system;

- Insufficient investment in education and training of managers and employees;

- Insufficient knowledge, skills and involvement in world economic trends;

- Lack of skills for developing European projects according to EU criteria;

- Lack of developing and implementing strategies and plans.

These results identify the points where business collaboration is most needed between organizations and the Faculty and underline the necessity for the Faculty to enrich its study programs with courses that elaborate the areas of: motivation system models, strategies and plans creation, global market strategies, EU project inclusion skills, business process optimization methodologies, business process improvement methods and techniques. The results are clearly shown in Figure 4. 


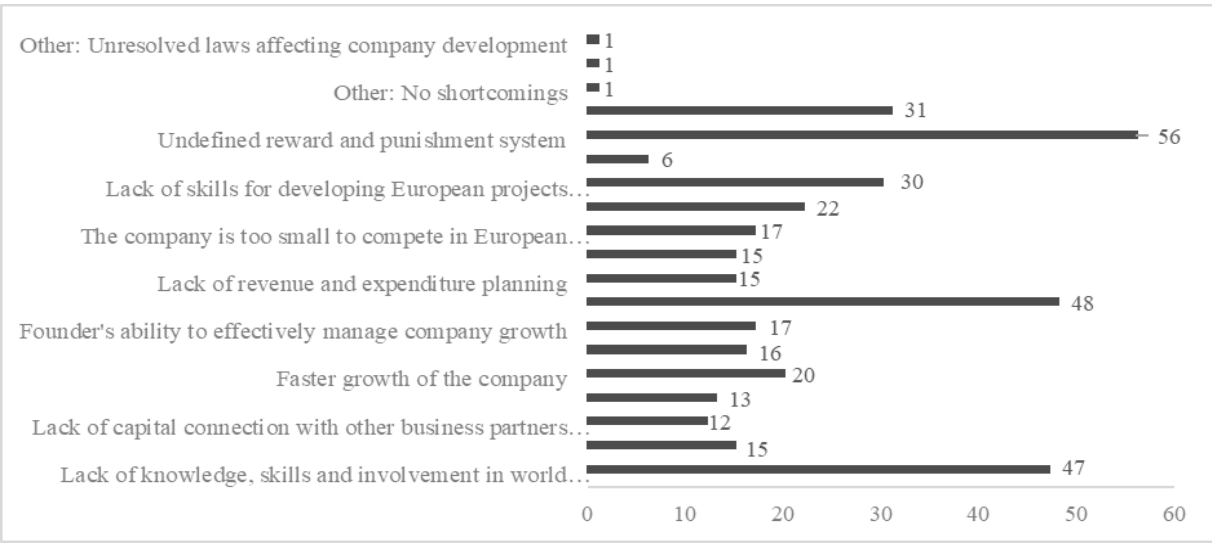

Fig.4. Deficiencies noted by organizations in the course of their work

The next question concerns the prior experience required of a candidate so as to be hired as a manager in surveyed organizations. The question aimed to determine how important previous experience and student internships are to organizational needs.

According to the results of the respondents, the highest values were obtained for the following employment criteria: Previously realized practical work in real-life systems as well as having entrepreneurial ideas and initiatives for business development and promotion, and the ability to work in a team.

Average values were obtained as follows: Realized student internships in other countries; High marks from undergraduate and/or postgraduate studies; Recommendations from professors and/or representatives from organizations where candidates completed practical work.

Low values were obtained for additional statements as criteria stated by the respondents themselves: Candidates shall be positive persons and must show the ability to face challenges; They must have a practical real-life school; They should be politically oriented; They have to show an ability to build interpersonal relationships, as well as skills in working with money.

These results identify the points where business collaboration is most needed between organizations and the Faculty and emphasize the need for 
business collaboration in order to create an opportunity for students to gain practical skills and experience with private and public sector employers since one of the prerequisites for integrating higher education staff into organizations is their prior hands-on experience. The results are clearly shown in Figure 5.

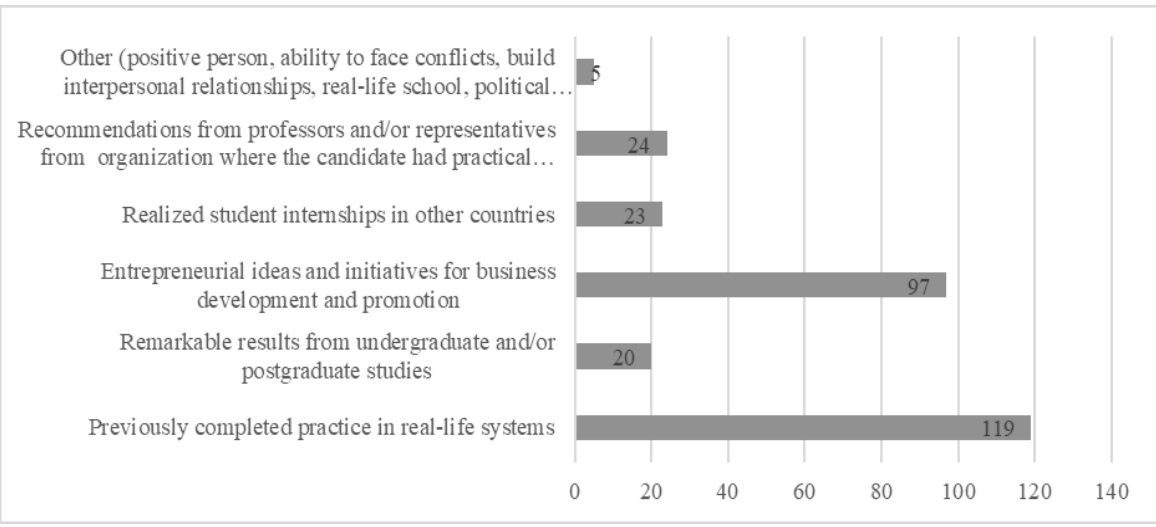

Fig.5. Required prior experience of candidates hired by the organization for a given managerial position

According to the results of the respondents (Figure 5), one of the respondents points to the politicization of state institutions where young people are also involved, and they see their future employment with the help of a political affiliation booklet.

Given the need to strengthen the capacity of organizations to run a business and to represent their interests, the research was particularly focused on identifying the competencies that a candidate should possess for the needs of organizations. The following question concerns the profile type of a candidate for a managerial position in organizations. The question was posed so as to determine which competencies the candidate should possess for the organizational needs. Respondents were offered 12 statements that encompassed possible competencies for running organizations and the opportunity for multiple responses. According to the results of the respondents, the highest values for the following aspects were obtained for the 
profile of managerial positions within their organization, namely: Excellent organizational and communication skills; Ability to work in a team; Ability to make quality decisions; Ability to resolve conflicts; Desire for professional development; Ability to risk analysis; Sales and marketing ability.

Medium values were obtained for: Management qualifications; Knowledge of quality systems and other management systems; Knowledge of energy saving tools: (Kaizen, 5S, Problem Solving, Value Stream Mapping, Total Productive Maintenance); Knowledge and understanding of the concepts of Continuous Improvement and Lean Manufacturing; Accounting/financial qualifications.

Low values were obtained for: persistent, honest and materially stable persons. These results identify the points that the Faculty needs to focus on and lead to the conclusion that it should enrich study programs with aspects that will help students gain knowledge, training and leadership skills. This outcome indicates the need for additional training and workshops for acquiring entrepreneurial skills of young students. The results are clearly shown in Figure 6.

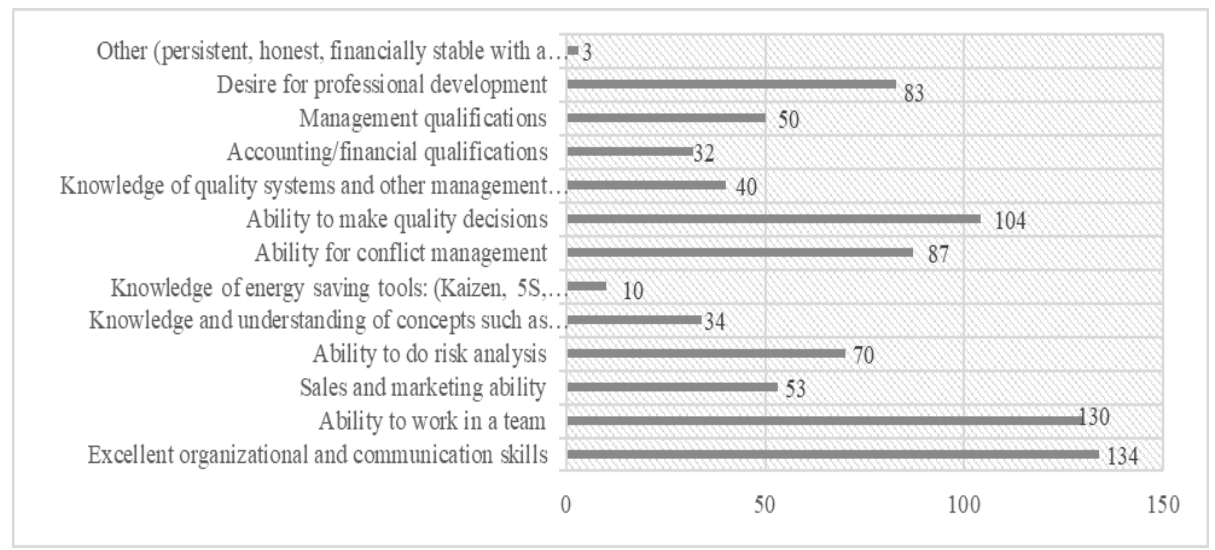

Fig.6. Knowledge and skills required of a candidate for a managerial position in organizations 
The next question concerns the idea whether organizations are familiar with the study program - Business Logistics at the Faculty of Tourism and Business Logistics at Goce Delchev University in Shtip. Respondents were offered the answers, yes, no and partially. The question was asked in order to determine how important it is for the Faculty to promote itself to the business community and state institutions.

The outcome of the respondents' answers is quite disturbing since out of 175 organizations - respondents, as much as 106 have not heard about the study program - Business Logistics at the Faculty of Tourism and Business Logistics at all, and 31 have been partially informed.

These results detect the areas where business collaboration is most needed between organizations and the Faculty and emphasize the need to strengthen business cooperation through participation in joint projects, training and events, without imposing the obligation on companies to have such students permanently employed.

Further examination refers to the idea whether organizations would like to be involved in the realization of student internships within their organizations enabling students to practically learn in real-life systems. Student internships should facilitate the student's transition from a passive consumer of information into an active, aware and responsible student who, while working on practical problems, contributes to his or her individual development as well as to the development of the internship organization/institution. These benefits are largely determined by the commitment and dedication of the student him/herself, but also by the institution where internships are carried out, as well as by the faculty as a necessary link in between. Student internship in the Republic of North Macedonia is still an underdeveloped field. According to the Rulebook on the Manner and Conditions for Organizing Practical Teaching, adopted by the Ministry of Education and Science (MES), practical teaching is compulsory for all students upon completion of the first year of their studies. Although this Rulebook was adopted in September 2010, no competent institution or stakeholder has made significant efforts to gain empirical insights into the implementation and impact of compulsory student internships for students at public and private universities in RNM (Article 7, Rulebook on the Manner and Conditions for Organizing Practical Teaching 
for Students (Official Gazette of the Republic of Macedonia, No. 35/08, 103/08, 26/09, 99/09 and 155/09).

Taking into consideration the business community's need for high-quality, strongly integrated staff in their organizations (as can be seen in Figure 5), respondents were asked how important it is for organizations to get involved in the practical teaching of students. Respondents were then offered yes/no answers.

According to the results of the respondents, as much as 95 out of 175 would not accept to be involved in the realization of practical education for students in their organizations.

These results pinpoint the areas in which business collaboration between organizations and the Faculty is most needed and lead to the conclusion that organizations must open the doors to student internships or offer other programs, with the opportunity for students to gain practical skills and experience.

The faculty should assist students in the process of adapting to the professional world by integrating practical work and theoretical instruction and providing appropriate mentoring. In particular, the Faculty should collaborate with local businesses in the process of creating paid work experience programs for their students, but Macedonian organizations should also offer and provide full support in the process.

The following question relates to whether organizations are willing to scholarship students to further integrate them into their organization. Respondents were offered yes/no answers. The question aims to determine how important it is for organizations to be involved in student development, but also to invest in recruiting high quality staff into their organizations.

In line with to the results of the respondents, 141 organizations out of 170 responded that they had no desire or interest to support scholarships for solid students to further integrate with them.

In the Republic of North Macedonia there are two models of practical work. One model is an internship program aimed at young students, giving them the opportunity to gain first-hand experience in education, as well as specific knowledge and skills through participation in the business community 
and institutions. Interns receive a monthly net allowance of MKD 5,043.00 (for this amount, personal income tax and insurance in the event of an accident at work and occupational disease is calculated and paid by organizations). However, only employers from the private and non-governmental sectors are eligible to participate.

Another model is the apprenticeships, that is, support for the acquisition of certain knowledge and skills by employers in the private sector, and applies to persons with secondary and tertiary education, postgraduates and other registered unemployed persons up to 29 years of age who have no previous work experience at the last level of study or their education profile. The funds are provided by the employer. This program covers young unemployed persons up to 29 years of age, persons with secondary and tertiary education and postgraduates for a period of 3 to 6 months. An unemployed young person may only use this Program once. The question arises whether this is enough.

The research results ascertain the areas in which business collaboration between organizations and the Faculty is most certainly needed and lead to the conclusion that links between organizations, scientific research and innovation must be strengthened. The outcome of the survey demonstrates the need for creative student internship programs designed by the Faculty but financially supported by the State and organizations.

The basic within the designing of such model is the redesign after which a new phase of education -continuous improvement, cycling the Deming's quality circle (Plan-Do-Check-Act) is followed. The necessity of redesign/ reengineering could arouse among those institutions that are willing to abandon the traditional approach by introduction of a new one, modern approach of education and science. Both approaches are based on same postulates: competences, abilities and knowledge but all those differently implemented according the technological development of the country and the higher educational systems in it. Planning the educational process is a task for the top management dulled to establish an education ward. This ward would have to prepare the plans and programmes in different levels for providing quality, in accordance with the functions and tasks that are being realized into an institution of higher education using the methodology and usage of Deming's circle of quality. The education of the employees into the whole structure of the higher educational institution is aiming to gain skills and 
experience into the realization of the educational processes. It is in accordance with the quality demands of the educational process, legal responsibilities and adequacy criteria as well as appointing the academic staff because the quality demands an involvement of each (everyone with their own work obligations). (Mitreva \& Prodanovska, 2012).

\section{Conclusion}

All in all, it is noticed to determine the needs of organizations to the extent that certain internal factors are present, with the intention of targeting higher education support needs. According to the results of the respondents, the highest values were obtained for human resources managers, then quality managers, followed by managers for logistics, marketing, finance, sales, public relations and international cooperation. Lower values were obtained for distribution managers. These results point to the conclusion that, coming from the objectives of the research, which is to identify the needs of Macedonian organizations for qualified potential, the results analysis has identified the areas in which the business community needs higher education support. It is precisely these areas that the Faculty should prioritize in the process of designing study programs for the needs of the business community by producing qualified workforce potential that will assist in achieving sustainable business systems.

The following recommendations can be made from the research:

1. There is a need for improving the study program: Business Logistics at FTBL should be in line with the specific needs of the business sector and its activities. The concluding results point out the areas in which the business community needs higher education support. It is precisely these areas that the Faculty should prioritize in the process of designing the study program: Business Logistics for the needs of the business community by producing qualified workforce potential in order to achieve sustainable business systems. 
Our research reveals that respondents involved in the research identified the main challenges/difficulties they face in running organizations:

- Undefined reward and punishment system;

- Insufficient investment in education and training of managers and employees;

- Insufficient knowledge, skills and involvement in world economic trends;

- Lack of skills for developing European projects according to EU criteria;

- Lack of developing and implementing strategies and plans.

These results identify the points where business collaboration is most needed between organizations and the Faculty and underline the necessity for the Faculty to enrich its study programs with courses that elaborate the areas of: motivation system models, strategies and plans creation, global market strategies, EU project inclusion skills, business process optimization methodologies, business process improvement methods and techniques.

2. Within the recognized and identified challenges that Macedonian organizations are facing, it is clear that in the future they will strive for the following occupational profiles: HR Managers; Quality Managers; Managers for Marketing; Business Logistics; Public Relations; Sales; Finance; Transport and Freight Forwarding; Integrated Management System Administration; International Cooperation; Coordination and Law Application.

3. This manner of aligning the needs of Macedonian organizations with the Faculty's programs can have a significant impact on economic development, and therefore, a coordinated approach is needed to promote the higher education system and the programs of the Faculty in order to respond to the challenges that organizations are facing, as well as to predict future needs for overcoming the labor demand mismatch with the education system.

The fact that a great number of organizations have not heard about the study program - Business Logistics at the Faculty of Tourism and Business Logistics. The outcome of the respondents' answers is quite disturbing since out of 175 organizations - respondents, as much as 106 have not heard about 
the study program - Business Logistics at the Faculty of Tourism and Business Logistics at all, and 31 have been partially informed.

These results detect the areas where business collaboration is most needed between organizations and the Faculty and emphasize the need to strengthen business cooperation through participation in joint projects, training and events, without imposing the obligation on companies to have such students permanently employed.

4. Promotion and enhancement of the curriculum of the study program: Business Logistics with courses for acquiring formal education but also for lifelong learning, in order to respond to the lack of technical skills and experience acquired both inside and outside formal education, and which are essential for the region-specific business sector.

Generally speaking, we can conclude that the organizations would not accept to be involved in the realization of practical education for students in their organizations.

According to the results of the respondents, as much as 95 out of 175 would not accept to be involved in the realization of practical education for students. in their organizations.

These results pinpoint the areas in which business collaboration between organizations and the Faculty is most needed and lead to the conclusion that organizations must open the doors to student internships or offer other programs, with the opportunity for students to gain practical skills and experience.

5. The faculty should bridge the gap between the knowledge the student gains in the higher education system and the skills that organizations require through mentoring, training and workshops, as well as through continuous interventions and support throughout the employment cycle, as well as through targeted skill development of students and their exploitation in reallife systems.

6. The faculty should achieve active cooperation between several stakeholders in the society (the Faculty, students, organizations, the local government and the state) in order to strike a balance between the demand and 
the supply on the labor market in terms of mismatching needs, with the aim to achieve a long lasting effect.

7. Encouraging student entrepreneurship initiatives and starting personal business ventures by the professors at the faculty.

8. There is a need for programs and projects that will focus graduates from the Faculty towards certain jobs and monitor their employment and career opportunities (for example, career centers, scholarship initiatives, career center student clubs, department or staff) to assist students in finding a job and keep track of graduates on one hand, whereas on the other hand (on the organizations' side), such programs appear as job offers, permanent filing of biographies and consultations on the number of high quality staff required. Hence, it is necessary to network and strengthen the links between organizations, scientific research work and innovations.

9. Paid internships for students and their on-the-job training as an approach, but also a tool for adjusting to the needs of organizations. This model needs to be widely accepted by companies as well as by students, using an integrated approach that involves more stakeholders such as the Faculty, the local government, the business community, etc. Having all this said, the workplace learning approach can also prove to be effective in building human capital especially for deficient positions within organizations.

10. Through the National Strategy for Development of Education in Macedonia the tendency of the state to conduct reforms in the education that would enable compatibility in the study programs, recognition of the diplomas acquired to all educational degrees in each part of Europe and increased capability for employment within the European labor market, has being offered. The system structure for providing quality into the institutions of higher education comprehends with the regulation even though there is a huge gap between the quality management and the attitude of performing quality.

11. Given that changing the curriculum is quite rigidly regulated by the Law on High Education, more flexible mechanisms to amend the program and 
so comply with the changes and trends in the labor market are necessary. It could be regulated at the level of authority of the educational institution, in which members of relevant government institutions and representatives of relevant sectors of the labor market can participate. It can be concluded that most of the teaching staff is aware of the necessity of creating skills among students corresponding to the labor market needs because one of their main objectives in teaching is gaining applicable skills and knowledge. However, these views are not fully reflected in the practices of teaching and assessment, as realistically they are a typically based on memorizing and reproducing the material.

\section{Limitations and future work}

The research was limited by several factors that can also serve as productive starting points for future work. First, it employed a relatively small set of indicators and could be enhanced by the addition of additional significant indicators to better identify how Macedonian organizations can work more efficiently and should focus themselves on improving the quality system and business collaboration between organizations and the Faculty.

These results identify the points where business collaboration is most needed and emphasize the need for business collaboration in order to create an opportunity for students to gain practical skills and experience with private and public sector employers since one of the prerequisites for integrating higher education staff into organizations is their prior hands-on experience.

Because the data was col-lected using an online questionnaire survey, the research may also suffer representation of the overall organizations in Republic of North Macedonia. As our research was characterised by a relatively small sample size, future work could focus on increasing the response rate, introducing other aspects of investigation, as well as spreading the target location to other countries.

Finally, instead of using one research technique, future research could employ multiple models and theories relevant to the assessment of the managerial perception on improving the quality system and business collaboration between organizations and the Faculty. 


\section{References}

Austin, A. E. (2002). Preparing the next generation of faculty: Graduate school as socialization to the academic career. The journal of higher education, 73(1), 94-122. https://doi.org/10.1080/00221546.2002.11777132

Austin, A. E., \& McDaniels, M. (2006). Preparing the professoriate of the future: Graduate student socialization for faculty roles. In HIGHER EDUCATION: (pp. 397-456). Springer, Dordrecht. [Google Scholar] Boyd, D. J., Grossman, P. L., Lankford, H., Loeb, S., \& Wyckoff, J. (2009). Teacher preparation and student achievement. Educational Evaluation and Policy Analysis, 31(4), 416-440. DOI: https://doi.org/10.3102/0162373709353129.

Bohdanowicz, P., Simanic, B., \& Martinac, I. (2005). Environmental training and measures at Scandic Hotels, Sweden. Tourism Review International, 9(1), 7-19.

Esyutina, M., Fearon, C., \& Leatherbarrow, N. (2013). The Bologna process in higher education: An exploratory case study in a Russian context. Quality Assurance in Education. DOI: https://doi.org/10.1108/09684881311310683.

Lee, J., Hong, N. L., \& Ling, N. L. (2001). An analysis of students' preparation for the virtual learning environment. The internet and higher education, 4(3-4), 231-242. [Google Scholar]

Mosneaga, A., \& Agergaard, J. (2012). Agents of internationalisation? Danish universities' practices for attracting international students. Globalisation, Societies and Education, 10(4), 519-538. DOI: https://doi.org/10.1080/14767724.2012.690309

Mitreva, E., Taskov, N., Milos, P., \& Gjorshevski, H. (2016). Measuring the quality of the high education in the Republic of Macedonia. IIASSInnovative Issues and Approaches in Social Sciences, 9(1), 163-180. DOI: http://dx.doi.org/10.12959/issn.1855-0541.IIASS-2016-no1art09

Mitreva, E., Taskov, N., Sazdova, J., \& Gjorshevski, H. (2015). The need to improve the educational process in high education institutions in the 
Republic of Macedonia by applying management methods and techniques. TTEM, 10(4), 467-475.

Mitreva, E., \& Prodanovska, V. (2012). The Management Teams are a Unique Business Potential that can Initiate, Identify and Manage Change within the Organization.

Medina-Muñoz, D., \& García-Falcón, J. M. (2000). Successful relationships between hotels and agencies. Annals of Tourism Research, 27(3), 737-762.

Rosser, V. J. (2003). Preparing and socializing new faculty members. The Review of Higher Education, 26(3), 387-395.

Sursock, A., Smidt, H., \& Davies, H. (2010). Trends 2010: A decade of change in European Higher Education (Vol. 1). Brussels: European University Association.

Smidt, H. (2015). European quality assurance-A European higher education area success story. In The European Higher Education Area (pp. 625637). Springer, Cham.

Sin, C. (2012). The Bologna master degree in search of an identity. European Journal of Higher Education, 2(2-3), 174-186. DOI: https://doi.org/10.1080/21568235.2012.702437

Taskov, N., \& Mitreva, E. (2015). The motivation and the efficient communication both are the essential pillar within the building of the TQM (total quality management) system within the Macedonian Higher Education Institutions. Procedia-Social and Behavioral Sciences, 180, 227-234. DOI: 10.1016/j.sbspro.2015.02.109 
Elizabeta Mitreva has a PhD from the University of Ss. Cyril and Methodius in Skopje, Macedonia (2010). She is currently working as a professor at the University of Goce Delcev in Stip, Republic of Macedonia. She is specialized for meaning and the perspectives of the designing and implementation on TQM (Total Quality Management) system from the viewpoint of researching of its participation within the domestic companies and creating a model methodology for improved performance, efficiency and effectiveness with the Macedonian companies through changing of the corporative culture and total utilizing of potentials.

Contact Address: Krste Misirkov. No.10-A Stip 2000. Republic of North Macedonia

E-mail: elizabeta.mitreva@ugd.edu.mk

Hristijan Gjorshevski. Born on 1996 in Bitola. In 2020 has received bachelor degree from the The Faculty of Computer Science and Engineering - FINKI, Univ. "Ss. Cyril and Methodius". He is currently working as a Software Engineer in Sia Soft to developing a next generation secure and anonymous communications protocol. He has published 2 co-authored exercise books, over 25 papers in the fields of TQM (Total Quality Management).

Contact Address: Macedonia, No. 58/1-6 Skopje, 1000, Republic of North Macedonia

E-mail: h.gjorshevski@gmail.com 